\title{
Эмпирический анализ экономической прибыли телекоммуникационных компаний в странах с развивающимися рынками капитала
}

\author{
Ивашковская И.В. ${ }^{11}$, Слободина М.В. ${ }^{12}$
}

В статье представлень результаты исследования роли экономической прибыли в объяснении рыночной капитализации 41 компании телекоммуникационной отрасли в группе стран BRIC, Центральной и Восточной Европь. Рассматриваются как простая форма показателя экономической прибыли, так и показатель с учетом поправок к данным об инвестированном капитале. На данной выборке получен вывод о высокой объясняющей способности экономической прибыли в то время, как традиционные бухгалтерские показатели доходности капитала оказались статистически не значимыми.

JEL: G30

Ключевые слова: экономическая прибыль, экономическая добавленная стоимость, развивающиеся рынки капитала, управление на основе стоимости, финансовый менеджмент

Использование экономической прибыли в оценке деятельности и в управлении капиталом рассматривается как современное направление финансового анализа компании, отвечающее новым тенденциям в экономике и растущим инвестиционным рискам в бизнесе. Эмпирические исследования экономической прибыли ведутся с 1990-х гг. и сосредоточены на проблеме ее роли в объяснении динамики рыночной стоимости компании, сравнительном анализе эффективности компаний, использующих принцип экономической прибыли в управлении. Каковы ключевые результаты эмпирических исследований? Какие выводы получены в эмпирических работах по компаниям с развивающихся (растущих) рынков капитала? В данной статье мы вносим собственный вклад в продолжающуюся дискуссию о силе и слабости показателей экономической прибыли для компаний с развивающихся рынков капитала.

\section{Обзор литературы и постановка задач исследования}

Основная часть исследований экономической прибыли выполнена на данных развитых стран, и полученные результаты противоречивы. В частности, выводы о более высокой объясняющей способности экономической прибыли сделаны в исследованиях С.Чена и Д.Додда, Г.Бидла и соавторо, С.Пейксото. П.Фернандеза, Д.Крамера и Д.Петерса [Chen, Dodd,1996; Biddle et al., 1999; Peixoto,1999; Fernandez, 2002; Kramer, Peters, 2001]. Напротив, в работах Г.Фельтхама и соавторов, А.Уорсигтона и Т.Уэста, Д.Мадитиноса и соавторов [Feltham et al., 2004; Worthigton, West, 2004; Maditinos et al., 2007] получены результаты, подтверждающие более высокую объясняющую способность экономической прибыли по сравнению с традиционными бухгалтерскими показателями. Несмотря на противоречивость имеющихся эмпирических результатов, проблема перехода к анализу компаний на основе экономической прибыли активно обсуждается в академической и прикладной литературе по развивающимся (растущим) рынкам капитала. Эти новые подходы уже внедрены в целом

\footnotetext{
${ }^{11}$ Профессор, заведующая кафедрой экономики и финансов фирмы, заведующая лабораторией корпоративных финансов ГУ-ВШЭ.

${ }_{12}^{2}$ Стажер-исследователь Лаборатории корпоративных финансов ГУ ВШЭ.

Выпуск \#2(10), 2009

(C) Электронный журнал Корпоративные Финансы, 2009
} 
ряде компаний таких стран. Например, в Бразилии в 1995 г. пивоваренная компания AmBev - третий по объемам выпуска производитель пива в мире - первой ввела систему управления на основе модели EVA®. В настоящее время в Бразилии эту модель внедрили около 40 компаний, но только 11 из них являются компаниями открытого типа.

$\mathrm{X}$. Суза и П. Джэнксо сравнили доходность акций бразильских компаний, полностью внедривших модель EVA®, с национальным индексом акций Ibovespa и с портфелем акций сравнимых по профилю компаний [Souza, Jancso, 2003]. По выбранным компаниям был построен индекс, взвешенный по их рыночной капитализации (MCW EVA). Показатели доходности сравнивались после коррекции на риск (risk adjusted profitability, RAP). Авторы установили, что значение индекса MCW EVA было выше индекса Ibovespa в среднем на 20\% в год. Сопоставление с портфелем аналогичных по профилю компаний также показало, что на протяжении всего периода наблюдений (февраль 1995 - сентябрь 2002 гг.) индекс MCW EVA был значительно выше, чем портфель сравнимых компаний. Выводы о более высокой объясняющей способности экономической прибыли получены по бразильским компаниям и в работе О.де Медеройса [de Mederois, 2005], где применен анализ корреляции изменений цены акции и изменений показателя EVA, взятого с лагом в один год $\left(E V A_{t-1}-E V A_{t-2}\right)$. Однако работа построена на малой выборке, поэтому автор считал полученные результаты предварительными.

В отличие от результатов по бразильским компаниям, в исследовании по компаниям Индии, выполненном Д. Рамана, не выявлено преимуществ экономической прибыли в объяснении изменений рыночной стоимости компании [Ramana, 2004]. В выборке за 19992003 гг. приблизительно 48\% компаний имели отрицательные значения экономической прибыли (EVA) и добавленной рыночной стоимости (MVA), 20\% компаний имели одновременно положительные значения EVA и MVA, а 5\% компаний имели положительные значения EVA и отрицательные значения MVA. Оставшиеся 27\% компаний имели положительные значения MVA, но отрицательные EVA. Оценка линейных регрессий показала более низкий коэффициент детерминации для независимой переменной экономической прибыли, чем для показателей бухгалтерской прибыли. Однако в спецификациях модели исследования, построенных на регрессии приростных значений независимых переменных, результаты противоположны: изменение экономической прибыли сильнее коррелирует с изменением MVA, чем изменения бухгалтерской прибыли. В более позднем исследовании по 1000 крупнейшим индийским нефинансовым компаниям Л. Ирала получил подтверждение более высокой объясняющей способности экономической прибыли [Irala, 2007].

Результаты, опровергающие гипотезу о более высокой объясняющей способности экономической прибыли, получены и в работах по выборкам тайваньских компаний за разные периоды [Liang, Yao, 2005; Huang, Wang, 2008] и компаний ЮAP [de Wet, 2005; DeVilliers, Auret, 1997]. Например, по данным 89 публичных промышленных компаний ЮАР за 1995-2004 гг. Д. де Вет выявил, что наиболее высокую объясняющую способность изменений добавленной рыночной стоимости (MVA) имеют показатели потока денежных средств (коэффициент детерминации 38\%), доходности совокупного капитала (коэффициент детерминации 15\%), а не экономическая прибыль [de Wet, 2005]. На другой выборке нефинансовых компаний ЮАР Д. де Вильер и С. Орэ показали, что прибыль на акцию (EPS) имеет более высокую объясняющую способность для изменений курсов акций, чем EVA [DeVilliers, Auret, 1997]. Однако в исследовании для более раннего периода (1987-1996 гг.). Д. Холл на выборке 200 промышленных компаний ЮАР получил противоположные результаты [Hall, 1998]. Анализ зависимости цены акции от ее балансовой стоимости, EVA и прибыли на акцию (EPS) с добавлением в модель прокси-переменных интеллектуального капитала проведен на выборке из 37 компаний, включенных в индекс тайваньской фондовой биржи, за 2001-2003 гг. Внесение таких прокси-переменных позволило увеличить объясняющую способность моделей, но не изменило вывода о том, что наиболее высокой объясняющей способностью обладает не экономическая прибыль, a EPS [Huang, Wang, 2008] 
Роль экономической прибыли в объяснении рыночной стоимости российских компаний постепенно становится предметом анализа в отечественной финансовоэкономической литературе [Бухвалов, Волков, 2005; Волков, Березинец, 2006; Романов, Кукина, 2008]. В последней работе в качестве зависимой переменной авторы применяют показатель совокупной доходности акций (total shareholder return, TSR) и на основе анализа панельных данных приходят к выводу о том, что экономическая прибыль изучаемой выборки российских компаний имеет низкую объясняющую способность.

В данном исследовании была поставлена задача выявить роль экономической прибыли в объяснении рыночной капитализации телекоммуникационных компаний стран с развивающимися рынками капитала, таких как группа BRIC, а также стран Центральной и Восточной Европы. Страны группы BRIC - это наиболее интересный объект наблюдений изза темпов их роста среди остальных стран с развивающимся рынком капитала. Высокая динамика предполагает, что компании данных стран раньше остальных внедряют новые концепции и технологии, используемые развитым рынком. Кроме того, интерес со стороны западных инвесторов стимулирует повышение качества раскрытия финансовой информации о компаниях. По численности населения и емкости рынка эти страны также являются лидерами. Это положительный фактор для телекоммуникационных компаний, так как результаты их деятельности напрямую зависят от величины абонентской базы. Выбор данной отрасли объясняется несколькими причинами. Во-первых, телекоммуникации по индексу популярности у инвесторов занимают первое место, опережая даже компании нефтегазовой отрасли, так как являются одной из самых быстроразвивающихся отраслей экономики. Поэтому информация о стоимости компании, а также методика повышения данного показателя являются наиболее ценной информацией как для собственников, так и для менеджмента компании. Во-вторых, в данной отрасли наблюдается высокий уровень конкуренции и заинтересованность в повышении эффективности деятельности. Наконец, управление компаниями этой отрасли наиболее приближено к западным аналогам, так как используется похожая политика продвижения и почти одновременно с западными компаниями внедряются новые технологии.

\section{Характеристика выборки и переменных моделей}

Из всех телекоммуникационных компаний в странах BRIC, Центральной и Восточной Европы выбирались только те, которые соответствовали следующим критериям:

1) публичные компании, опубликовавшие свою финансовую отчетность за период с 2002 по 2007 гг. в формате US GAAP или IFRS;

2) предоставление услуг мобильной и фиксированной связи (компании, занимающиеся производством телекоммуникационного оборудования, в выборку не включались);

3) телекоммуникационные услуги должны приносить как минимум $30 \%$ выручки всей компании.

Для поиска информации о компаниях использовались база EMEI, целью которой является публикация информации о компаниях, работающих на развивающихся рынках, и Factiva, публикующая информацию о деятельности компании за длительный период времени, текущие финансовые и нефинансовые показатели, данные о совете директоров. В результате данного отбора в выборку была включена 41 компания из Бразилии (6), Индии (9), Китая (7), России (12), Восточной Европы - Болгария (2), Украина (1); Центральной Европы - Чехия (1), Словения (1), Венгрия (2).

В сформированной выборке были выделены компании, фактически применяющие принципы управления на основе стоимости и показатели экономической прибыли в своей деятельности. С этой целью данные были собраны с сайтов компаний и путем запроса в консалтинговую компанию Strern\&Stewart. Однако получить официальное подтверждение факта применения концепций экономической прибыли удалось не во всех случаях. Поэтому в таблице 1 в ряде случаев оставлены пропуски. 
Таблица 1.

Распределение компаний по признаку «внедрившие - не внедрившие» EVA

\begin{tabular}{|c|c|}
\hline Компании, не внедрившие EVA & Компании, внедрившие EVA \\
\hline \multicolumn{2}{|c|}{ Бразилия } \\
\hline $\begin{array}{l}\text { Telecomunicacoes de Sao Paulo, Embratel, } \\
\text { TIM, Tele Norte Leste }\end{array}$ & Brasil Telecom, Telemar, Vivo \\
\hline \multicolumn{2}{|l|}{ Индия } \\
\hline $\begin{array}{l}\text { Avaya Global Connect Ltd., Dhanus } \\
\text { Technologies Ltd., Spanco Telesystems \& } \\
\text { Solutions Limited, XL Telecom Ltd. }\end{array}$ & $\begin{array}{l}\text { Bharti Airtel Limited, GTL Limited, } \\
\text { Mahanagar Telephone Nigam Limited, Tata } \\
\text { Teleservices (Maharashtra) Limited, Reliance } \\
\text { Communications Ltd. }\end{array}$ \\
\hline \multicolumn{2}{|r|}{ Россия } \\
\hline $\begin{array}{l}\text { МГТС, } \quad \text { Комстар, Башинформсвязь, } \\
\text { Вымпелком, Волгателеком, Дальсвязь, } \\
\text { Ростелеком, Северозападный } \\
\text { Сибирьтелеком, телеком, Таттелеком, } \\
\text { Уралсвязьинформ, Центртелеком }\end{array}$ & MTC \\
\hline \multicolumn{2}{|l|}{1} \\
\hline $\begin{array}{l}\text { China Satcom Guomai Communications, } \\
\text { Shenzhen Coship Electronics Ltd., Beijing } \\
\text { Bewinner Communications Ltd., } \\
\text { Corporation, ZTE } \\
\text { Telecommunications China } \\
\text { Communications Services Ltd. }\end{array}$ & China Telecom Corporation Ltd. \\
\hline \multicolumn{2}{|c|}{ Центральная Европа } \\
\hline $\begin{array}{l}\text { Telefonica O2 } \\
\text { (Словия), }\end{array}$ & \\
\hline \multicolumn{2}{|c|}{ Восточная Европа } \\
\hline $\begin{array}{l}\text { Bulgarska telekomunikatsionna komp AD } \\
\text { (Болгария), Eurocapital Bitex AD Sofia } \\
\text { (Болгария), Ukrtelekom VAT (Украина) }\end{array}$ & \\
\hline
\end{tabular}

Модель исследования направлена на выявление зависимости капитализации компании от результатов ее деятельности, выраженных в форме традиционных бухгалтерских показателей и в форме экономической прибыли.

В итоговую выборку вошла 41 компания, с максимальным периодом наблюдения в пять лет, с 2003 по 2007 гг., и с минимальным - в два года, с 2006 по 2007 гг.; всего было получено 163 наблюдений в виде несбалансированной панели. Дескриптивная статистика данных представлена в таблице 2. Помимо показателя рыночной капитализации собственного капитала (MVE) использованы показатели прибыли на акцию (EPS), доходности совокупного капитала (ROA), доходности собственного капитала (ROE), экономической прибыли в форме экономической добавленной стоимости, то есть с учетом поправок к данным финансовой отчетности ( $\left.E V A^{a d j}\right)$, а также применявшиеся для внесения поправок данные о коммерческих расходах и расходах на рекламу ( $S A E x)$, величине нематериальных активов (IA) и совокупных активов (BVA). 
Таблица 2

Описательная статистика данных

\begin{tabular}{|l|c|c|c|c|c|}
\hline \multicolumn{1}{|c|}{ Переменная } & $\begin{array}{c}\text { Число } \\
\text { наблюдений }\end{array}$ & Средняя & $\begin{array}{c}\text { Стандартное } \\
\text { отклонение }\end{array}$ & Минимум & Максимум \\
\hline MVE, тыс. долл. & 163 & $1,91 \mathrm{e}+07$ & $8,88 \mathrm{e}+07$ & 64220 & $8,47 \mathrm{e}+08$ \\
\hline EPS, долл. & 163 & 0,1308589 & 0,2045392 & $-0,09$ & 1,17 \\
\hline ROA, \% & 163 & 0,0919018 & 0,0994215 & $-0,12$ & 0,9 \\
\hline ROE, \% & 163 & 0,1097546 & 0,1112163 & $-0,33$ & 0,48 \\
\hline EVA adj, тыс. долл. & 163 & 265900 & 853003,8 & $-880483,8$ & 4881711 \\
\hline IA, тыс. долл. & 163 & 248140,5 & 430520,9 & 0 & 2468600 \\
\hline SAEx, тыс. долл. & 163 & 214912,7 & 398427,9 & 0 & 2206322 \\
\hline BVA, тыс. долл. & 163 & 5312745 & 9457914 & 5345 & $5,59 \mathrm{e}+07$ \\
\hline
\end{tabular}

На основе таблицы 2 можно выявить ряд характеристик компаний, входящих в выборку. Во-первых, анализ средних значений и значений стандартного отклонения от среднего свидетельствует о том, что величина рыночной (MVA) и экономической добавленной стоимости $\left(\mathrm{EVA}_{\mathrm{adj}},\right)$, а также показатели эффективности деятельности коэффициенты рентабельности (ROE, ROA) - положительны, но при этом в рамках исследуемой выборки их значения невысокие. Аналогичные выводы также характерны и для коммерческих расходов, расходов на рекламу (SAEx) и нематериальных активов (IA).Данный факт можно объяснить тем, что наблюдается большой разброс данных, а также ограниченность выборки. Наряду с большим количеством небольших компаний в выборке присутствует ряд фирм-гигантов (анализ показателя BVA), представляющих собой крупные холдинги, а также компании, работающих при поддержке государства.

Во-вторых, при исследовании отдельных компаний можно сделать вывод о том, что не все фирмы демонстрировали положительную экономическую добавленную стоимость и эффективную деятельность на протяжении исследуемого периода времени. Для ряда компаний в отдельные годы было характерно разрушение стоимости. Это могло быть связано с неэффективной деятельностью менеджмента, нестабильной ситуацией в отрасли и в стране, выходом на рынок сильного конкурента.

Чтобы учесть размер компании, рыночная капитализация нормирована на совокупную балансовую стоимость активов $\left(\frac{M V E}{B V A}\right)$. Аналогичный подход применен и к показателю экономической прибыли, рассчитанному с учетом поправок $\left(\frac{E V A^{a d j}}{B V A}\right)$. Описательная статистика данных с учетом нормирования приведена в таблице 3.

Таблица 3.

Описательная статистика данных, нормированных на величину балансовой стоимости активов

\begin{tabular}{|l|c|c|c|c|c|}
\hline Переменная & $\begin{array}{c}\text { Число } \\
\text { наблюдений }\end{array}$ & Средняя & $\begin{array}{c}\text { Стандартное } \\
\text { отклонение }\end{array}$ & Минимум & Максимум \\
\hline$\frac{M V E}{B V A}$ & 163 & 23,15074 & 136,9259 & 0,15 & 954,42 \\
\hline$\frac{E V A^{a d j}}{B V A}$ & 163 & 0,623681 & 3,85709 & $-0,22$ & 33,84 \\
\hline
\end{tabular}


При выборе тестируемых спецификаций моделей учитывалась корреляция показателей с нормированной экономической прибылью. Переменные, имеющие высокую корреляцию, из спецификации модели одновременно не выключались.

Взаимосвязи капитализации и экономической прибыли исследованы на основе финансовой модели анализа компании [Ивашковская, 2007]. С этой целью для выражения результатов деятельности использованы упрощенная форма независимой переменной экономической прибыли (residual income, RI) и экономическая добавленная стоимость $\left(E V A_{i t}^{a d j}\right)$. Последний показатель построен путем внесения поправок в данные финансовой отчетности i-той компании в год $t$, составляющих так называемые «эквиваленты собственного капитала» (equity equivalents) в составе инвестированного в компанию капитала [Stewart, 1991]. Отличия финансового подхода к анализу капитала, предполагающего выход за пределы формальных показателей финансовой отчетности и направленного на более полное отражение ресурсов, используемых компаниями в конкуренции, рассмотрены в работах И.В. Ивашковской [Ивашковская, 2007; Ивашковская, 2008]. Использование независимой переменной $E V A_{i t}^{a d j}$ направлено на то, чтобы определить, позволит ли добавление поправок к данным финансовой отчетности улучшить качество исследовательской модели и результатов.

Экономическая добавленная стоимость рассчитывалась, как показано в уравнении 1:

$$
E V A_{i t}^{a d j}=N O P A T_{i t}^{a d j}-W A C C_{i t} \cdot \times C a p I n v_{i t}^{a d j},
$$

где:

NOPAT $T_{i t}^{a d j}$ - прибыль от основной деятельности, скорректированная с учетом капитализации части расходов;

CapInv $v_{i t}^{a d j}$ - инвестированный капитала i-компании в год $\mathrm{t}$ с учетом поправок;

$W A C C_{i t}-$ средневзвешенная ставка затрат на капитал i-компании в год $\mathrm{t}$.

Для определения показателя NOPAT $T_{i t}^{a d j}$ по компаниям выборки были внесены поправки, выбранные с учетом особенностей телекоммуникационной отрасли. При анализе финансовой отчетности компаний было выявлено несколько фактов. Во-первых, большинство компаний из выборки не амортизируют репутацию, а в момент переоценки активов списывают определенную долю этого актива. Поэтому поправки, связанные с возвратом суммы, начисленной по активу «репутация» амортизации, не нужны. Во-вторых, по остальным нематериальным активам амортизация начислялась, поэтому поправки на амортизацию нематериальных активов учтены. В-третьих, только небольшое число компаний выборки публикует информацию о расходах на исследования и разработки (R\&D). Кроме того, чаще всего величина данных расходов незначительна, поэтому ее пришлось исключить из расчетов. В-четвертых, в рамках данного исследования было сделано предположение о том, что инвестиционная часть коммерческих расходов и расходов на рекламу составляет $100 \%$, и они капитализируются полностью. Амортизация коммерческих расходов рассчитывалась методом равномерных списаний на основании продолжительности жизненного цикла компаний телекоммуникационной отрасли, составляющего в среднем 5 лет.

(2)

$$
N O P A T_{i t}^{a d j}=E B I T_{i t} \times(1-t)+I D D_{i t}+A m I A_{i t}+I D T_{i t}+\operatorname{CapSAEx}_{i t}-A_{m} \operatorname{CapSAEx}{ }_{i t},
$$

где:

$I D D_{i t}$ - increase in doubtful debts - увеличение резерва по сомнительной задолженности i-компании за год t; 
$A m I A_{i t}$ - amortization of intangible assets - амортизация нематериальных активов ікомпании за год $\mathrm{t}$;

$I D T_{i t}$ - increase in deferred tax - увеличение отложенных налоговых платежей iкомпании за год $\mathrm{t}$;

$\operatorname{CapSAEx}_{i t}$ - capitalized selling and advertising expense - капитализированные коммерческие расходы и расходы рекламу і-компании за год $\mathrm{t}$;

AmCapSAEx ${ }_{i t}$ - amortization of capitalized selling and advertising expense - амортизация коммерческих расходов и расходов на рекламу і-компании за год $\mathrm{t}$;

$\mathrm{t}$ - ставка налога на прибыль.

Для расчета экономической добавленной стоимости инвестированный капитал определен, как показано в уравнении 3:

$$
C E_{i t}^{a d j}=\text { Shares }_{i t}+\text { Min }_{i t}+R E_{i t}+\text { Loans }_{i t}+\text { AcAmIA }_{i t}+D D_{i t}+D T_{i t}+\text { CapSAEx }_{i t},
$$

где:

Shares $_{i t}$ - балансовая стоимость обыкновенных и привилегированных акций iкомпании по состоянию на конец года $\mathrm{t}$;

Min $_{i t}$ - minority interest - доля миноритариев в собственном капитале i-компании по состоянию на конец года $\mathrm{t}$;

$R E_{i t}$ - retained earnings - величина нераспределенной прибыли і-компании по состоянию на конец года $\mathrm{t}$;

Loans $_{i t}$ - балансовая стоимость краткосрочных и долгосрочных кредитов и займов, процентов по ним, обязательств по финансовому лизингу і-компании по состоянию на конец года $\mathrm{t}$;

$A c A m I A_{i t}$ - accumulated amortization of intangible assets - накопленная амортизация нематериальных активов і-компании по состоянию на конец года $\mathrm{t}$;

$\operatorname{CapSAEx}_{i t}$ - capitalized selling and advertising expense - капитализированные коммерческие расходы и расходы на рекламу і-компании за год $\mathrm{t}$;

$D D_{i t}$ - doubtful debts - резерв по сомнительной задолженности i-компании за год $\mathrm{t}$;

$D T_{i t}$ - deferred tax - отложенные налоговые обязательства i-компании за год $\mathrm{t}$.

Средневзвешенные ставки затрат на капитал (WACC) рассчитаны на основе данных о балансовой стоимости заемного и собственного капиталов. Затраты на заемный капитал $\left(K d_{i t}\right)$ определены для i-компании в год $\mathrm{t}$ методом синтетического кредитного рейтинга. Затраты на собственный капитал $\left(K e_{i t}\right)$ для i-компании в год $\mathrm{t}$ рассчитаны на основе гибридной модели методом спреда доходности. Безрисковая ставка доходности для рынка США $\left(R_{f}\right)$ оценивается для каждого года как скорректированная краткосрочная ставка по усредненным месячным данным на историческом интервале в 30 лет, соответствующем средней жизни инвестора (например, 1978-2007 гг.). Показатель равен разнице между текущей доходностью 20-летних казначейских векселей США и спредом за горизонт прогнозирования (на основе исторической разницы в доходности 20-летних казначейских облигаций и трехмесячных векселей). Премия за рыночный риск США $\left(R_{m}-R_{f}\right)$ рассчитывается как историческая разница месячных доходностей индекса S\&P500 и трехмесячных казначейских векселей США. Страновая премия за риск (CRP) ежегодно определяется для каждой страны на основе рейтинга страны по шкале Moody's, представленного на сайте www.damodaran.com. Величина бета для каждой компании из выборки определялась на базе отраслевых бета для компаний, представленных на сайте www.damodaran.com. 


\section{Модель исследования}

Исследовательская модель построена на основе однофакторных и многофакторных регрессий. Базовая спецификация модели представлена уравнением 4:

$$
\frac{M V E_{i t}}{B V A_{i t}}=b_{0}+b_{1} \cdot X_{i t}+\varepsilon_{i t},
$$

где:

$M V E_{i t}$ - Market Value of Equity - капитализация собственного капитала і-компании в год $\mathrm{t}$;

$B V A_{i t}$ - Book Value of Assets - балансовая стоимость совокупных активов і-компании на конец года $\mathrm{t}$;

$X_{i t}$ - показатель результата деятельности $i$-компании за год $t$, рассмотренный поочередно через бухгалтерские показатели доходности капитала и через экономическую прибыль;

$b_{0} .-$ свободный член;

$b_{1}-$ коэффициент при независимой переменной;

$\varepsilon_{i t}$ - случайная ошибка.

На основе базовой спецификации модели последовательно тестировались гипотезы о прямой зависимости рыночной капитализации собственного капитала от экономической прибыли, рассчитанной с поправками к инвестированному капиталу ( $\left.E V A^{\text {adj }}\right)$ и без них $(R I)$, и от традиционных бухгалтерских показателей доходности капитала (ROA, ROE). Показатели экономической прибыли нормированы на величину балансовой стоимости активов. Учитывая целесообразность отражения в текущем значении капитализации компании ожиданий инвесторов, сформированных на основе информации об экономической прибыли, рассчитанной за предыдущий финансовый год, в дополнительных спецификациях модели в качестве независимой переменной выступает лаговая переменная экономической прибыли $\frac{E V A_{i t-1}^{a d j}}{B V A_{i t-1}}$. Тестируемая гипотеза о прямой зависимости рыночной капитализации от прошлых результатов деятельности компании, выраженных в форме экономической прибыли, в которой учтен финансовый подход к капиталу, основана на следующей модели:

$$
\frac{M V E_{i t}}{B V A_{i t}}=b_{0}+b_{1} \cdot \frac{E V A_{i t-1}^{a d j}}{B V A_{i t-1}}+\varepsilon_{i t} \text {. }
$$

На ожидания инвесторов оказывают влияние не только результаты деятельности компании за прошлый год, но также и текущие новости и информация о результативности ее работы. Для тестирования влияния текущих и прошлых экономических прибылей выдвинута дополнительная гипотеза: Капитализация компании находится в прямой зависимости от прошлых и текущих результатов ее деятельности, выраженных в форме экономической прибыли, в которой учтен финансовый подход к капиталу. Поэтому модель специфицирована следующим образом:

$$
\frac{M V E_{i t}}{B V A_{i t}}=b_{0}+b_{1} \cdot \frac{E V A_{i t}^{a d j}}{B V A_{i t}}+b_{2} \cdot \frac{E V A_{i t-1}^{a d j}}{B V A_{i t-1}}+\varepsilon_{i t} .
$$

Для подтверждения гипотезы нужно, чтобы результаты удовлетворили следующим условиям: $b_{1}>0, b_{2}>0$. 
Интерпретация финансовых показателей инвесторами может зависеть от типа финансовой отчетности, используемой компанией, а также от деловой среды страны, в которой она работает. Поэтому, как показано в уравнении 7 , рассматривалась дополнительная спецификация модели с фиктивными (дамми) переменными. Подобная модификация применена и к модели с лаговыми независимыми переменными.

$$
\frac{M V E_{i t}}{B V A_{i t}}=b_{0}+b_{1} \cdot \frac{E V A_{i t}^{a d j}}{B V A_{i t}}+b_{2} \cdot R O E_{i t}+b_{3} \cdot D_{1}+b_{4} \cdot D_{2}+b_{5} \cdot S_{1}+b_{6} \cdot S_{2}+b_{7} \cdot S_{3}+b_{8} \cdot S_{4}+\varepsilon_{i t},
$$

где:

$\mathrm{D}_{1}, \mathrm{D}_{2}$ - дамми-переменная типа финансовой отчетности. Для компаний, использующих стандарт отчетности US GAAP, $\mathrm{D}_{1}=1$; для тех, которые используют IFRS или местные стандарты, $\mathrm{D}_{1}=0$; для тех фирм, которые публикуют отчетность в формате IFRS, $\mathrm{D}_{2}=1$; для остальных $\mathrm{D}_{2}=0$.

$\mathrm{S}_{1}-\mathrm{S}_{4}$ - дамми-переменная страны. Для российских компаний $\mathrm{S}_{1}=1$, для остальных $\mathrm{S}_{1}$ $=0$; по такому же принципу определяется значение для остальных дамми-переменных. Для китайских компаний $\mathrm{S}_{2}=1$, для индийских $\mathrm{S}_{3}=1$, для бразильских $\mathrm{S}_{4}=1$. Для компаний, работающих в странах Центральной и Восточной Европы, все дамми-переменные равны 0.

Учитывая, что в выборку попали компании, действительно внедрившие экономическую прибыль в свои аналитические и управленческие практики, была использована дополнительная спецификация модели с фиктивной переменной $K$. Эта переменная введена (уравнение 8) для тестирования влияния на рыночную стоимость компании, которое может оказывать построение системы управления капиталом компании на основе принципов экономической прибыли. На наш взгляд, внедрение этих подходов в управленческие практики в телекоммуникационных компаниях может вести к более высоким темпам роста стоимости компании, чем у аналогов. Поэтому дополнительная зависимость, которая проверялась в исследовании, состоит в следующем: изменение капитализации компании положительно зависит от изменения величины экономической прибыли, и у компаний, внедривших модель EVA, капитализация растет более быстрыми темпами. С этой целью использовалась дополнительная спецификация модели:

$$
\Delta \frac{M V E_{i t}}{B V A_{i t}}=b_{0}+b_{1} \cdot \Delta \frac{E V A_{i t}^{a d j}}{B V A_{i t}}+b_{2} \cdot K+\varepsilon_{i t} \text {, }
$$

где:

$K$ - это дамми-переменная внедрения и использования экономической прибыли; $K=1$ для компаний, внедривших концепцию EVA и открыто заявивших об этом; для всех остальных фирм выборки $K=0$.

\section{Анализ результатов}

В результате оценивания построенных регрессионных моделей нами получены интересные выводы. Результаты регрессионного анализа приведены в Приложении. Вопервых, тестирование базовой модели (уравнение 4) выявило, что для данной выборки компаний показатели, относящиеся к традиционной системе управления на основе бухгалтерской аналитической модели (ROA, ROE), оказались статистически незначимыми. Оба показателя экономической прибыли - RI и EVA - обладают высокой объясняющей способностью (коэффициенты детерминации 77 и 78,7\% соответственно). Данные результаты наглядно представлены в таблице 4. 
Результаты тестирования зависимости MVE/BVA от фактора X

\begin{tabular}{|l|c|c|c|}
\hline Фактор $(\boldsymbol{X})$ & $\mathbf{R}^{\mathbf{2}}$ & Коэффициент $\left(\boldsymbol{b}_{\mathbf{1}}\right)$ & P-value \\
\hline$\frac{E V A}{B V A}$ & $\mathbf{0 , 7 8 7}$ & 31,51 & 0,00 \\
\hline$\frac{R I}{B V A}$ & $\mathbf{0 , 7 7}$ & 28,43 & 0,00 \\
\hline$R O A$ & 0,0014 & 52,21 & 0,254 \\
\hline$R O E$ & 0,0004 & 25,11 & 0,439 \\
\hline
\end{tabular}

Второй важный результат состоит в том, что наиболее высокой объясняющей силой в описании зависимой переменной - рыночной капитализации собственного капитала рассмотренных телекоммуникационных компаний стран BRIC, Восточной и Центральной Европы обладает экономическая добавленная стоимость, рассчитанная с учетом поправок к инвестированному капиталу. Этот результат позволяет ставить вопрос о целесообразности развертывания в компаниях данной отрасли управления на основе создания стоимости и использования экономической прибыли для оценивания результатов деятельности компаний и их подразделений.

В-третьих, оценивание регрессий с лаговой переменной экономической прибыли показало, что такая спецификация модели обладает самой высокой объясняющей способностью (уравнения 5 и 6). Этот результат, представленный в таблице 5 , совпадает с выводами исследований последних лет об особой роли фактора ожиданий в формировании рыночной капитализации и показателей полной доходности акций (total shareholder return,TSR) [Copeland et al., 2005].

Таблица 5.

Результаты тестирования регрессий с лаговой EVA

\begin{tabular}{|l|c|c|c|c|}
\hline & \multicolumn{2}{|c|}{ Регрессия (5) } & \multicolumn{2}{c|}{ Регрессия (6) } \\
\hline$R^{2}$ & \multicolumn{2}{|c|}{0,6631} & \multicolumn{2}{c|}{$\mathbf{0 , 7 8 8}$} \\
\hline Переменные & Коэффициент & P-value & Коэффициент & P-value \\
\hline Константа, $b_{0}$ & 5,777 & 0,407 & $-1,038548$ & 0,413 \\
\hline$\frac{E V A_{t-1}^{\text {adj }}}{B V A_{t-1}}$ & 27,956 & 0,000 & 6,182085 & 0,004 \\
\hline$\frac{E V A_{t}^{\text {adj }}}{B V A_{t}}$ & - & - & 26,94849 & 0,000 \\
\hline
\end{tabular}

Однако ряд выдвинутых гипотез не подтвердились на данной выборке компаний. Тестирование спецификации модели с фиктивными переменными стран и типа финансовой отчетности (уравнение 7) выявило, что эти дополнительные независимые переменные для данной выборки компаний оказались незначимыми (таблица 6). 
Таблица 6.

Результаты оценивания многофакторной регрессии со скорректированной независимой переменной экономической прибыли (EVA $\left.{ }_{\text {adj }}\right)$, ROE и другими дамми-переменными

\begin{tabular}{|l|c|c|}
\hline & \multicolumn{2}{|c|}{ Регрессия (7) } \\
\hline$R^{2}$ & \multicolumn{2}{|c|}{0,806} \\
\hline Переменные & Коэффициент & P-value \\
\hline Константа, $b_{0}$ & 81,479 & 0,261 \\
\hline$\frac{E A_{t}^{\text {adj }}}{B V A_{t}}$ & 29,046 & 0,000 \\
\hline$R O E$ & & 0,179 \\
\hline$D 1$ & $-28,243$ & 0,427 \\
\hline$D 2$ & 1,541 & 0,179 \\
\hline$S 1$ & $-3,917$ & 0,256 \\
\hline$S 2$ & $-80,027$ & 0,300 \\
\hline$S 3$ & $-73,446$ & 0,275 \\
\hline$S 4$ & $-77,473$ & 0,265 \\
\hline
\end{tabular}

Наконец, тестирование спецификации модели, в которой учитывался факт использования концепции управления на основе стоимости (уравнение 8), так же не привело к выводам о значимости этого отличия. Коэффициент при dummy-переменной $K$, отражающей факт внедрения концепции EVA конкретной компанией, оказался не значим. Данный результат мог быть получен по нескольким причинам. Во-первых, из-за небольшого количества в выборке компаний, открыто заявивших, что они используют методику EVA. Во-вторых, среди компаний, для которых $\mathrm{K}=0$, также могут присутствовать те, что фактически используют экономическую прибыль, но не заявляют об этом в открытых источниках информации.

Таблица 7.

Результаты оценивания многофакторной регрессии с изменением скорректированной независимой переменной экономической прибыли (EVA adj) и дамми-переменной K

\begin{tabular}{|l|c|c|}
\hline & \multicolumn{2}{|c|}{ Регрессия (8) } \\
\hline$R^{2}$ & \multicolumn{2}{|c|}{0,738} \\
\hline Переменные & Коэффициент & P-value \\
\hline Константа, $b_{0}$ & $-0,829$ & 0,482 \\
\hline$\Delta \frac{E V A_{t}^{a d j}}{B V A_{t}}$ & 4,996 & 0,000 \\
\hline$K$ & 1,026 & 0,403 \\
\hline
\end{tabular}

Несмотря на то что ряд гипотез не нашли подтверждения, мы считаем, что пример телекоммуникационной отрасли показывает, что использование экономической прибыли это действенный инструмент в контроле за созданием стоимости и оценке результатов компании на развивающихся рынках капитала на основе стоимости.

\section{Список литературы}

1. Бухвалов А.В., Волков Д.Л. Исследование зависимости между фундаментальной ценностью и рыночной капитализацией российских компаний // Вестник СанктПетербургского университета. Серия Менеджмент. - 2005. -. № 1. - С. 26-44. 
2. Березинец И.В., Волков Д.Л. Управление ценностью: анализ, основанный на бухгалтерских показателях моделей оценки: Научные доклады НИИ менеджмента СПбГУ. - 2006. - № 3.

3. Ивашковская И.В. Финансовые измерения корпоративных стратегий // Аудит и финансовый анализ. - 2007. - № 5. - С. 150-163.

4. Ивашковская И.В. Модель стратегического стоимостного анализа фирмы // Экономическая наука современной России. - 2008. - № 3. - С.111-115

5. Biddle, G.C., Bowen, R.M., and Wallace, J.S. (1999), Evidence on EVA, Journal of Applied Corporate Finance, 12 (2) (1999) 69-79.

6. Chen, S., Dodd, J. (2002), Market Efficiency, CAPM, and Value-relevance of Earnings and EVA: A Reply to the Comment by Professor Paulo, Journal of Managerial Issues, 14 (4) (2002) 507-512.

7. Chen, S., Dodd, J.L. (1996), EVA: A new panacea?, Business \& Economic Review (July September 1996) 26-28.

8. Copeland, T., Dolgoff, A., Moel, A. (2004), The Role of Expectations in the Cross-section of Returns, The Review of Accounting Studies, 9 (2-3) (2004) 149-188.

9. De Medeiros O.R. (2005), Empirical Evidence on the Relationship Between EVA and Stock Returns in Brazilian Firms, 2005, SSRN-id701421.

10. De Villiers, J.U., Auret, C.J. (1997), A Comparison of EPS and EVA as explanatory variables for share price, Journal for Studies in Economics and Econometrics (August 1997).

11. De Wet, J. (2005), EVA versus traditional accounting measures of performance as drivers of shareholder value - A comparative analysis, Meditari Accountancy Research, 13 (2) (2005) 1-16.

12. Feltham, G., Grant, J., Mbagwu, C, Vaidyanathan, G. Perhaps EVA Does Beat EarningRevisiting Previous Evidence, Journal of Applied Corporate Finance. 16 (16) (2004), 8388.

13. Fernandez P. EVA, Economic Profit, Cash Value Added do NOT Measure Shareholder Value Creation. Working Paper. IESE Business School, 2002.

14. Hall, J.H. (1998), Variables determining shareholder value of industrial companies listed on the Johannesburg Stock Exchange. Doctoral thesis, University of Pretoria, Pretoria, 1998.

15. Huang, C., Wang, M. (2005), The Effects of Economic Value added and intellectual capital on the Market Value of firms: An Empirical Study, International Journal of Management, 25 (3) (2005).

16. Irala, L.R. (2007), Corporate Performance Measures in India: An Empirical Analysis// URL: http://papers.ssrn.com/ abstract_id=964375.

17. Kramer, J.K., Peters, J. R. (2001), An interindustry analysis of economic value added as a proxy for market value added, Journal of Applied Finance, 11 (1) (2001) 41-49.

18. Liang, C., Yao, M. (2005), The Value-Relevance of Financial and Nonfinancial Information - Evidence from Taiwan's Information Electronics Industry, Review of Quantitative Finance and Accounting, 24 (2005) 135-157.

19. Maditinos, D., Sevic, Z., Theriou, N., Dimitriadis, E. (2007), The Use Of Traditional And Modern Value-Based Performance Measures To Evaluate Companies' Implemented and Future Strategies In The Greek Capital Market: The Case of EPS and EVA, Journal of International Research Publications, 2 (2007) 35-50.

20. Peixoto S. Economic Value Added ${ }^{\circledR}$ - Application to Portuguese Public Companies: Moderna University of Porto Working Paper. URL: http://papers.ssrn.com/ abstract_id $=302687$.

21. Ramana, D.V. (2005), Market value added and economic value added: some empirical evidence// URL: http://papers.ssrn.com/abstract_id=871404. 
22. Souza, J.G.C., Jancso, P. (2003), Does it pay to implement a full scale EVA® management system? Evidence from Brazilian companies// URL: http://papers.ssrn.com/ abstract_id $=381541$.

23. Stewart, G. B., Bennett III (1991), The quest for value: a guide for senior managers, Harper Business.

24. Worthigton, A, West, T. (2004), Australian Evidence Concerning the Information Content of Economic Value Added, Australian Journal of Management (December 2004). 